\section{Atypical piloleiomyoma of the face presenting with central ulceration}

\author{
Alessandro Pileri, Pier Luigi Ghetti, \\ Iria Neri, Beatrice Raone, Selena Ciabatti, \\ Camilla Reggiani, Annalisa Patrizi \\ Department of Internal Medicine, \\ Geriatrics and Nephrology, Division of \\ Dermatology, University of Bologna, Italy
}

\begin{abstract}
Piloleimyoma is a type of cutaneous leiomyoma arising from arrectores pilorum. It can present as either a solitary nodule or multiple lesions. Usually it is localized on the extremities, but can also occur on trunk, neck area and face. Lesions are usually cold, ulcerated and spontaneously painful. Herein we report a case of piloleiomyoma with cytological atypia that was painless despite the presence of central ulceration.
\end{abstract}

\section{Case Report}

In November 2006, a 23-year-old woman referred to the Department of Dermatology of Bologna University with a two-month-history of a softy painless nodule located on the right cheek (Figure 1). Physical examination revealed a yellowish lesion that showed a central ulceration measuring $2 \mathrm{~cm}$ across and infiltrating the sub-cutis. Based on macroscopic appearance and anamnesis, a cutaneous Leishmaniasis was suspected: in particular, the patient had spent 3 months on the Sardinia coast where Leishmania is endemic. However, neither cytological nor cultural examination did confirm such hypothesis. Therefore, an incisional biopsy was performed under local anaesthesia that was fixed in formalin and embedded in paraffin, according to routine procedures. Light microscopy showed that the nodule consisted of spindle-cells with slight cytological atypia, a moderate amount of eosinophilic cytoplasm, oval or elongated nuclei, and small but distinct nucleoli. They formed interweaving bundles and infiltrate the dermis and sub-cutis. The overlaying epidermis was acanthotic with central ulceration and necrosis. Some mitotic figures were present (3/10HPF), more numerous in the ulcerated areas. At immunohistochemistry, neoplastic elements expressed smooth-muscle actin but were negative for CD34, CD68/PG-M1 and protein S-100. ${ }^{1}$ The Ki-67/MIB-1 rate was low ( $<5 \%$ on average) with the exception of a thin area surrounding the ulceration. According to macroscopic, histological and phenotypic findings, a diagnosis of atypical piloleiomyoma was made. The lesion was surgically removed: its examination confirmed the diagnosis. At four-year-follow up, the patient is alive and well with no sign of disease.

\section{Discussion}

Cutaneous leiomyomas, first described in 1854 by Rudolf Virchow, ${ }^{2}$ are benign, smoothmuscle tumours. In particular, piloleiomyoma arises from the arrectores pilorum of the skin. It more often presents as a solitary, non-ulcerated, painful nodule. Microscopically, it corresponds to a non-encapsulated lesion, consisting of bland, interwoven fusiform cells with a central small nucleus. ${ }^{3}$ So far, cellular atypia has been reported only by Harford et $a l .{ }^{4}$ in a case that is somewhat reminiscent of our own observation. In particular, the present case confirms that, like leiomyomas of other anatomic sites, piloleiomyoma can at times be provided with features of cellular atypia, a fact that suggests to periodically follow-up the patient because of the risk, although low, of recurrences. Interestingly, our patient has so far remained in complete remission, a finding that is of interest since no information on the clinical outcome were provided by Harford and co-workers. ${ }^{4}$ In addition,

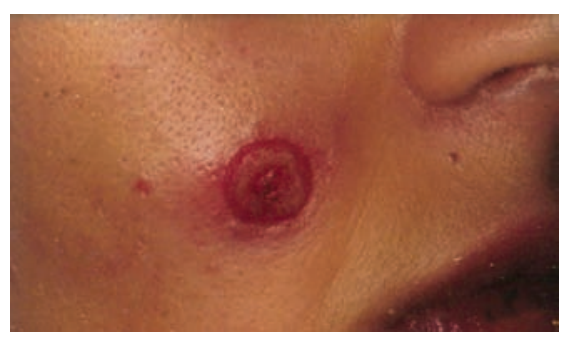

Figure 1. Softy painless nodule located on the right cheek.
Correspondence: Alessandro Pileri, Department of Internal Medicine, Aging and Nephrological diseases, Division of Dermatology, University of Bologna, Via Massarenti 1, Bologna, Italy Tel. +39.051.636.3475 - Fax: +39.051.636.3920. E-mail: alessandropileri@hotmail.it

Key words: piloleiomyoma, surgical excision, immunohistochemestry.

Received for publication: 25 July 2011.

Revision received: 1 October 2011

Accepted for publication: 6 September 2011.

This work is licensed under a Creative Commons Attribution NonCommercial 3.0 License (CC BYNC 3.0).

(C) Copyright A. Pileri et al., 2011

Licensee PAGEPress, Italy

Dermatology Reports 2011; 3:e50

doi:10.4081/dr.2011.e50

our case unusually presented with an ulcerative lesion in the absence of spontaneous or evoked pain. This along with the anamnestic data initially led to suspect cutaneous Leishmaniasis. It was the biopsy which allowed the correct diagnosis that was validated by immunohistochemistry. Based on our observation, we think that clinicians should consider atypical leiomyoma in case of a non-healing ulcer with bizarre clinical features.

\section{References}

1. Sabattini E, Bisgaard K, Ascani S, et al. The EnVision++ system: a new immunohistochemical method for diagnostics and research. Critical comparison with the APAAP, ChemMate, CSA, LABC, and SABC techniques. J Clin Pathol 1998;51:506-11.

2. Virchow R. Ueber carvernose (erectile) geschwulste und teleangiektasien. Arch Pathol Anat Physiol Klin Med 1854;6:52554.

3. Lever WF, Schaumburg-Lever G. Histopatology of the Skin, 7 th. Ed. JB Lippincott; Philadelphia: 1990.

4. Harford RR, Vidmar DA, Cobb MW, et al. An atypical piloleiomyoma presenting as a nonhealing ulcerated nodule. Cutis 1996;57:168-70. 